\title{
Spontaneous pregnancy in a patient with premature ovarian insufficiency after a failed attempt of ovulation induction
}

\author{
Nasuha Yaacob*, Fadzlin M. Adzlan, Siti Nabillah Ab Rahman
}

Department of Obstetrics and Gynaecology, Hospital Sultanah, Nur Zahirah, Kuala Terengganu, Malaysia

Received: 16 July 2021

Revised: 14 August 2021

Accepted: 17 August 2021

\section{*Correspondence:}

Dr. Nasuha Yaacob,

E-mail: nasyaacob@yahoo.com

Copyright: ( ) the author(s), publisher and licensee Medip Academy. This is an open-access article distributed under the terms of the Creative Commons Attribution Non-Commercial License, which permits unrestricted non-commercial use, distribution, and reproduction in any medium, provided the original work is properly cited.

\section{ABSTRACT}

Premature ovarian insufficiency (POI) is defined as intermittent or permanent gonadal insufficiency before age of 40 years. POI causes female infertility hence pregnancies are uncommon but not impossible. Ovarian failure is not permanent, unlike menopause. There could be intermittent ovulation and spontaneous pregnancy. Many protocols aimed to restore ovarian functions have been described in the recent years. This is a case of POI women who conceived spontaneously in the immediate menstrual cycle after a failed attempt at ovarian stimulation following many years on hormone replacement therapy (HRT). She had an unremarkable pregnancy and delivered a healthy baby via caesarean section.

Keywords: Premature ovarian failure, Premature ovarian insufficiency, Gonadal insufficiency, Ovulation induction, Hypergonadotrophic hypogonadism

\section{INTRODUCTION}

Premature ovarian insufficiency (POI) is a current preferred term for premature ovarian failure (POF). ${ }^{1}$ POI is defined as intermittent or permanent gonadal insufficiency before age of 40 years. The incidence is 1 in 1000 women before the age of 30 and 1 in 100 women at 40 years. $^{2}$ Women may present with amenorrhea or irregular menses (oligoamenorrhea more than 4 months), with highly elevated follicle stimulating hormone (FSH) above $25 \mathrm{mIU} / \mathrm{ml}^{3}$ Anti-Mullerian hormone (AMH) would be invariably very low, with undetectable number of ovarian antral follicle count (AFC) on ultrasound. ${ }^{4}$

Although POI has many causes ranging from genetic, autoimmune or infective, most causes are unknown. ${ }^{5}$ POI causes female infertility hence pregnancies are uncommon but not impossible. ${ }^{6}$ We report a case of POI woman who conceived spontaneously after a failed attempt at ovarian stimulation following many years on hormone replacement therapy (HRT).

\section{CASE REPORT}

Madam NS, a 27 years old woman was diagnosed with POF at the age of 23 when she had secondary amenorrhea of one year. She had her menarche at 12 years old, initially regular monthly menses then reduced to oligomenorrhea once or twice a year by the end of her adolescent years. Her serum FSH upon initial presentation another specialist hospital was $60 \mathrm{mIU} / \mathrm{ml}$ and serum estradiol was less than $50 \mathrm{pmol} / \mathrm{L}$. Her serum prolactin and thyroid stimulating hormone (TSH) were within normal range. She was started on cyclical HRT using estradiol hemihydrate $1 \mathrm{mg}$ and dydrogesterone $10 \mathrm{mg}$ (Femoston 1/10, Abbot) that she had tolerated it well. She had gotten married and did not think of trying to conceive until 2 years later. The couple was then referred to our reproductive service, with primary infertility for 2 years for assisted conception. Her AMH 
level was at a very low level of $0.07 \mathrm{pmol} / \mathrm{l}$. She has normal chromosomal study of 46, XX. Screening for autoimmune causes were normal. Pelvic transvaginal ultrasound found no pathology. She had hysterosalphingogram (HSG) done which revealed a normal but small uterine cavity and her both fallopian tubes were patent. Her husband's semen analysis (SA) was of normal quality.

The couple had an extensive counselling on their slim chance of conception and the range of fertility treatment options including adoption. They were keen for a trial treatment of ovulation induction using exogenous injections of gonadotrophins once her FSH level lowered to below $25 \mathrm{mIU} / \mathrm{l}$. Her HRT protocol was changed to estradiol valerate $2 \mathrm{mg}$ and norgestrel $500 \mathrm{mcg}$ (Progyluton, Bayer) for 6 months and serial serum FSH taken were $50 \mathrm{mIU} / \mathrm{ml}$ at 3 months and $34 \mathrm{mIU} / \mathrm{ml}$ at 6 months. We changed the hormone therapy to estrogen only using estradiol valearate (Progynova, Bayer) $4 \mathrm{mg}$ daily. After 2 weeks of estradiol valerate treatment, her serum FSH reduced further to $21 \mathrm{mIU} / \mathrm{ml}$.

Transvaginal scan (TVS) showed a visible small $(1 \times 1.2 \times 1.5 \mathrm{~cm})$ left ovary with antral follicle count (AFC) of 1. Serum FSH and estradiol levels were taken on same day as the commencement of incremental dosage of urofollitrophin injection (SC Folliculin, Firstline) between 75-150 IU daily. They were $18 \mathrm{mIU} / \mathrm{ml}$ and $448 \mathrm{pmol} / \mathrm{l}$ respectively (Table 1). After 12 days of ovarian induction, serial TVS observed no follicle growth in both ovaries. She was not keen to continue the daily injections. Stimulation protocol was abandoned and she was started back on HRT after she had the withdrawal bleeding. She was planned for another attempt at ovulation induction after 3 months of HRT.

She checked self-urine pregnancy test (UPT) when there was no withdrawal bleeding after one cycle of HRT Progyluton. She had an unexpected spontaneous pregnancy that was immediately supported with oral dydrogesterone $10 \mathrm{mg}$ BD (Duphaston, Abbott) and vaginal micronised progesterone $200 \mathrm{mg}$ ON (Utrogestan, Wellchem/Besins). Two weeks later, ultrasound showed an intrauterine gestational sac with a presence of fetus and fetal heart pulsations. We closely monitored her until 12 weeks of her pregnancy. Detail scan at 22 weeks of gestation showed a grossly normal fetus. The remaining of her antenatal course was unremarkable. She successfully delivered a healthy baby boy with a birth weight of 3.17 $\mathrm{kg}$ via elective caesarean section at term. Intraoperatively, the right and left ovaries were both present in sizes of $3.0 \times 1.6 \times 0.8 \mathrm{~cm}$ and $2.6 \times 1.3 \times 0.5 \mathrm{~cm}$ respectively (Figure 1). Currently at 6 months postnatal, she has an established successful exclusive breastfeeding and still remained amenorrheic. She is not keen for any modern contraception and aware of risk of unexpected intermittent ovarian activity. She wished to resume HRT once her baby is 9 months old.

Table 1: Trends of hormone pattern while on estrogen treatment and at commencement of ovarian stimulation.

\begin{tabular}{|llllll|} 
Hormone & Baseline & $\begin{array}{l}\mathbf{3} \text { months of } \\
\text { progyluton }\end{array}$ & $\begin{array}{l}\mathbf{6} \text { months of } \\
\text { progyluton }\end{array}$ & $\begin{array}{l}\mathbf{2} \text { weeks of } \\
\text { estradiol valerate }\end{array}$ & $\begin{array}{l}\text { On day } \mathbf{1} \text { of } \\
\text { SC follitropin }\end{array}$ \\
\hline FSH (mIU/ml) & 60 & 50 & 34 & 21 & 18 \\
\hline Serum estradiol $(\mathbf{p m o l} / \mathbf{l})$ & $<50$ & NA & NA & NA & 448 \\
\hline
\end{tabular}

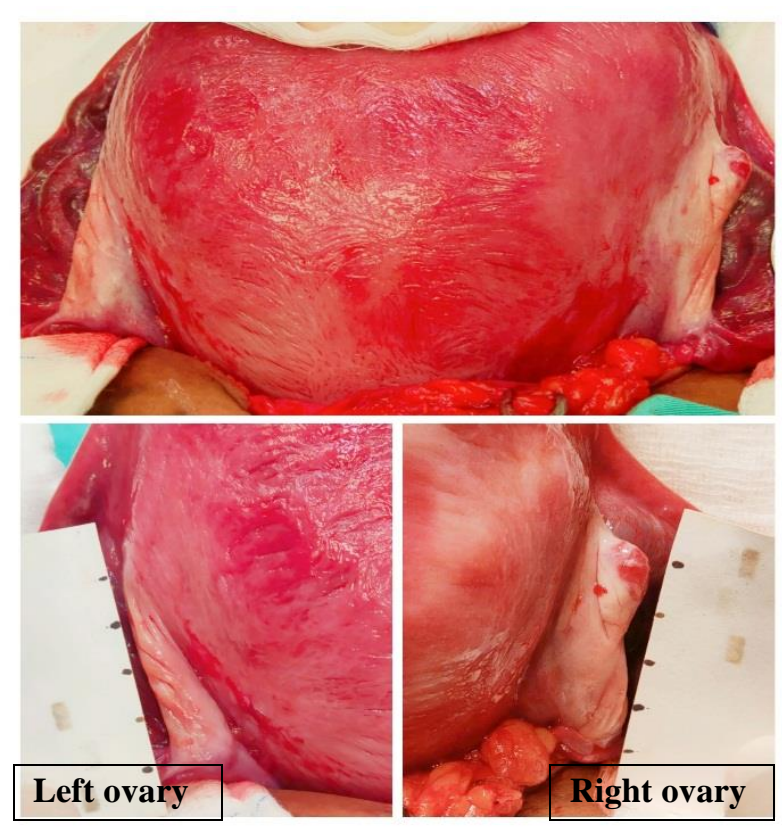

Figure 1: Ovaries seen at caesarean section.

\section{DISCUSSION}

Ovarian failure in POI is not permanent, unlike menopause. Primordial and pre-antral follicles often found in ovarian biopsies of POI women. ${ }^{6}$ There could be intermittent ovarian activities, $5 \%$ of these women may conceive spontaneously. ${ }^{5}$ Others resort to assisted conception via donor oocyte programme, as it is the most effective treatment to enable them to obtain parenthood. By using donor eggs, the pregnancy rates goes up markedly. ${ }^{7,8}$ However, having own biological child could be the only permissible option for some women due to various reasons including religion prohibition, legal restriction or cultural taboo.

Many protocols aimed to restore ovarian functions have been described in the recent years to fulfil the couple's wish for their own genetic child. Pregnancies have been reported from patients treated with HRT. ${ }^{9-11}$ Suppressing the high level of circulating serum FSH with exogenous estrogen may downregulate gonadotrophins receptors to regenerate and regain responsiveness to hormone stimulation. ${ }^{11-13}$ Lowering LH could also help to improve 
oocyte quality by preventing early luteinisation. Ovulation induction with concomittant use of corticosteroids to reduce perifollicular inflammatory macrophages has resulted in pregnancies in autoimmune-related POI. ${ }^{14}$

To the authors' knowledge, this is the first reported case of spontaneous conception in the immediate cycle after failed attempt at ovarian stimulation of ovarian activity and ovulation induction. Serial ultrasound monitoring did not show follicular growth hence gonadotrophin was discontinued. Although unsuccessful, exogenous estrogen followed by gonadotrophins had likely exerted a significant ovarian priming acitivity thus increasing ovarian sensitivity to de-novo FSH and HRT to initiate follicular growth and ovulation. Keeping serum FSH below $15 \mathrm{mIU} / \mathrm{ml}$ before starting ovulation induction has resulted in successful pregnancies. ${ }^{12,13}$

\section{CONCLUSION}

Spontaneous pregnancies in POI women are not likely to be high risk of maternal or neonatal morbidities as compared to general background population. It has a favourable perinatal outcome, resulting in birth of a healthy child. Despite strong association with infertility, it is crucial to advise patient about family planning using modern method to space their pregnancies since intermittent resumption of ovarian activities is possible yet unpredictable. POI is a complex disease with a wide variety of causes. Thus far, there is no treatment for its infertility has so far shown superiority.

\section{ACKNOWLEDGEMENTS}

The authors would like to thank the Director General of Health Malaysia for the permission to publish this paper.

Funding: No funding sources

Conflict of interest: None declared

Ethical approval: Not required

\section{REFERENCES}

1. Panay N, Anderson RA, Nappi RE, Vincent AJ, Vujovic S, Webber L, et al. Premature ovarian insufficiency: an International Menopause Society White Paper, Climacteric. 2020;23(5):426-46.

2. Coulam CB, Adamson SC, Annegers JF. Incidence of premature ovarian failure. Obstet Gynecol. 1986;67:604-6.
3. European Society for Human Reproduction and Embryology (ESHRE) Guideline Group on POI; Webber L, Davies M, Anderson R, Bartlett J, Braat D, et al. ESHRE guideline: management of women with premature ovarian insufficiency. Hum Reprod. 2016;31:926-37.

4. De Vos M, Devroey P, Fauser BC. Primary ovarian insufficiency. Lancet. 2010;376:911-21.

5. Nelson LM. Clinical practice: primary ovarian insufficiency. N Engl J Med. 2009;360:606-14

6. Bidet M, Bachelot A, Bissauge E. Resumption of ovarian function and pregnancies in 358 patients with premature ovarian failure. J Clinical Endocrinol Metab. 2011;96:3864-72.

7. Oyesanya OA, Olufowobi O, Ross W, Sharif K, Afnan M. Prognosis of oocyte donation cycles: a prospective comparison of the in vitro fertilizationembryo transfer cycles of recipients who used shared oocytes versus those who used altruistic donors. Fertil Steril. 2009;92:930-6.

8. Paulson RJ, Hatch IE, Lobo RA, Sauer MV. Cumulative conception and live birth rates after oocyte donation: implications regarding endometrial receptivity. Hum Reprod. 1997;12(4):835-9.

9. Gu Y, Xu Y. Successful Spontaneous Pregnancy and Live Birth in a Woman With Premature Ovarian Insufficiency and 10 Years of Amenorrhea: A Case Report. Front Med. 2020;7:18.

10. Dragojević Dikić S, Rakić S, Nikolić B, Popovac S. Hormone replacement therapy and succesful pregnancy in a patient with premature ovarian failure. Gynecol Endocrinol. 2009;25:769-72.

11. Tartagni M, Cicinelli E, De Pergola G. Effect of pretreatment with estrogens on ovarian stimulation with gonadotropins in women with premature ovarian failure: a randomized, placebo controlled trial. Fertil Steril. 2007;87:858-61.

12. Ben-Nagi J, Panay N. Premature ovarian insufficiency: how to improve reproductive outcome? Climacteric. 2014;17:242-6.

13. Badawi A, Goda H, Ragab A. Induction of Ovulation in idiopathic premature ovarian failure: a randomised double-blind trial. Reprod Bio Med Online. 2007;15(2):215-9.

Cite this article as: Yaacob N, Adzlan FM, Ab

Rahman SN. Spontaneous pregnancy in a patient with premature ovarian insufficiency after a failed attempt of ovulation induction. Int J Reprod Contracept Obstet Gynecol 2021;10:3584-6. 